\title{
ArChivo y nOVELA. Sobre La DIMENSIÓN MUSEAL DE LA LITERATURA LATINOAMERICANA *
}

\author{
Juan D. Cid Hidalgo**
}

\section{Resumen}

Con este trabajo queremos reparar sobre cierta sensibilidad museal presente en la novela $D e$ sobremesa (1925) del modernista colombiano José Asunción Silva. En esta novela se registra, por medio del diario de vida del insatisfecho e idealista poeta José Fernández, una compleja serie discursiva sobre el estado de crisis en que se encuentra el intelectual latinoamericano y el arte finisecular. La curatoría a que es sometida la memoria pareciera ser un elemento de importancia en que novela y museo se emparentan, fundamentalmente por su manejo de aquello que Roberto González Echevarría ha denominado «ficciones de archivo» (2000). El texto suprime las distancias entre colección y coleccionista a partir de la no jerarquización de los objetos, de manera que el acto de coleccionar se transforma en pura acumulación.

Palabras clave: archivo, novela, memoria, ficciones del archivo, De sobremesa.

\section{Archive And nOvel. About MUSEUM Dimension of LATin AMERICAN LITERATURE}

\begin{abstract}
In this research, we want to notice certain museum dimension that is in the novel by modernist Colombian author Jose Asunción Silva. De sobremesa (1925) is a novel where a complex discursive series about the state of the crisis in which Latin American intellectual people and fin-de-siècle art is registered, by the diary of the unsatisfied and idealist poet Jose Fernandez. The curator's work, in which memory is submitted, seems to be an important aspect where novel and museum are related, mainly in the use of what Roberto Gonzalez Echevarría has called «archival fictions» (2000). The text suppresses the distances between collection and collector from the non-hierarchy of objects, so that the act of collecting becomes pure accumulation.
\end{abstract}

Keywords: archive, novel, memory, archival fictions, De sobremesa.

Recibido: 15-01-2016

Aceptado: 02-04-2016

Este trabajo forma parte de una investigación mayor denominada Apuntes sobre la dimensión museal de la literatura latinoamericana o los museos de papel. Proyecto FONDECYT No 11121221.

* Chileno. Doctor en Literatura Latinoamericana de la Universidad de Concepción. Académico de la Universidad de Concepción, Concepción, Chile. jdcid@udec.cl 
Yo me volví un coleccionista, a falta de ella, buscando consuelo en cosas adyacentes.

Cristina Peri Rossi

\section{Introducción}

El trabajo con la constitución de la memoria pareciera ser uno de los elementos de importancia en que novela y museo se emparentan, fundamentalmente, por su manejo de aquello que Roberto González Echevarría (2000) ha denominado «ficciones del Archivo» (2000), materializaciones narrativas que denotan la obsesión textual de la literatura latinoamericana por el archivo, factor fundamental en la articulación memorial de un proyecto, doctrina o credo. En este sentido creemos pertinente instalar la figura del museo dentro de aquel selecto grupo de espacios que Pierre Nora (2009) ha llamado «lugares de memoria», con lo cual éste adquiere una nueva dimensión que pone en entredicho el inmovilismo al cual ha sido permanentemente asociado y, al mismo tiempo, se lo consagra como dispositivo. Para el historiador francés ha existido una especie de disociación entre experiencia y pasado que, por lo visto, solo se puede morigerar en la medida en que vayamos alimentando la ley del recuerdo: «Si habitáramos nuestra memoria, no tendríamos necesidad de consagrarle lugares» (20) expresa Nora de entrada en su Pierre Nora en Les lieux de mémoire (2009), estudio que surge a partir de la curiosidad por conocer los lugares donde se refugia o cristaliza la memoria, espacios que paradójicamente nacen debido a una ausencia o a una falta de espontaneidad. «Los lugares de la memoria nacen y viven del sentimiento de que no hay memoria espontánea, de que hay que crear archivos, mantener aniversarios, organizar celebraciones, pronunciar elogios fúnebres, labrar actas, porque esas operaciones no son naturales» $(24)$.

Para comenzar señalaremos una primera complejidad y una primera decisión metodológica. «Es evidente que no puede describirse exhaustivamente el archivo de una sociedad, de una cultura, de una civilización» (Foucault 221), aunque sí podemos apuntar que lo «archivado» en los museos y colecciones constituye un acercamiento a lo que esa sociedad o civilización pretende sea una base simbólica de su relato histórico orientado en tal o cual dirección, en un intento 
permanente de singularizarse y definirse a partir de lo que podríamos llamar memorización del pasado.

Así como el museo -aquel clásico receptáculo de archivos- conjura el olvido, la novela, o el carácter memorial de los textos, otorga al museo de papel un rol singular donde archivo, escritura, colección y curatoría se transforman en ideas articuladoras de un ejercicio de poder restaurador del pasado y vitalizador del futuro. Son estas coordenadas las que nos ayudarán a percibir una zona de enorme interés en el contexto de la narrativa latinoamericana que ha incursionado en los territorios de vecindad entre arte y escritura.

En primera instancia no debemos olvidar que el antecedente anterior a la formación de los museos como los conocemos hoy es la práctica del coleccionismo ${ }^{1}$, actividad especialmente fecunda en el siglo XVIII, fundamentalmente por erigirse como una práctica legitimadora de un cierto estatus, sostén de una imagen superior de clase y, paradójicamente, una forma de exhibición, no precisamente de lo valioso de los objetos recolectados, sino de la capacidad económica y la excentricidad del coleccionista que irrumpe exactamente en el momento en que el capitalismo hace su aparición (Blom, 2013). Sin embargo, aunque el coleccionismo es una mezcla de deseo de posesión, curiosidad intelectual y, por supuesto, ansia de reconocimiento social, también es articulación memorial de un ideario curatorial que necesariamente se convierte en práctica de la memoria, en tanto que se impone sobre objetos del pasado a la vez que transforma el museo en dispositivo ${ }^{2}$ de poder cuando el coleccionismo deviene institución y edificación arquitectónica y simbólica. Américo Castilla en El museo en escena. Política y cultura en América Latina (2010) sostiene una idea que percibimos aquí con toda propiedad, es la idea de que la memoria es una construcción política en que la solitaria actividad del coleccionista como la transitada actividad

Recomendamos la lectura de «Evolución del concepto de museo» (1992) de Francisca Hernández. Jean-Louis Déotte (1998), por su lado, suma la noción de aparato como una configuración técnica del aparecer, idea que nos hace comprender cómo el museo (las colecciones, inventarios, archivos, etc.) visibiliza las imágenes, a la vez que nos hace comprenderlo como una superficie de inscripción, por lo tanto, registro de una memoria al porvenir, como una actividad de selección memorial (curatoría) que, como los tribunales, escoge qué recordar y qué olvidar: «Por tribunal no hay que entender solamente la institución jurídica sino más allá, sus procedimientos, su trabajo de pesquisa, la identificación de objetos testimoniales, la autenticación crítica, el registro, la comparecencia de las partes, la decisión, la ejecución, etc.» (24). 
museal se convierten en dispositivos que al momento de estudiarlos manifiestan «la construcción de poder que allí se ponía en escena» (19). ${ }^{3}$

A continuación, para explicarnos el modo en que la novela se acerca a la discusión respecto de una dimensión museal de su quehacer nos detendremos en De sobremesa (1925), novela del escritor modernista colombiano José Asunción Silva, texto escrito muy accidentadamente entre 1887 y1896 y que es «reflejo del más alto intelectualismo de finales del siglo XIX» (García Maffla 4479)4. Esta novela de artista (Gutiérrez Girardot, 1987), construida por entregas a modo de diario, nos retrata -mediante la lectura del mismo- la vida de un poeta insatisfecho a la vez que idealista llamado José Fernández, quien alrededor de una mesa en su casa y, luego de comer junto a unos amigos, pasa revista al estado de crisis en que se encuentra la intelectualidad latinoamericana y por extensión el estado del arte a fines del siglo XIX. ${ }^{5}$

Tras años en París $^{6}$, el poeta José Fernández regresa a Bogotá convertido en un dandy tan refinado como rebelde, a la vez que lleno de contradicciones. Trae consigo una obsesión que pone en el centro la preocupación y la manía por los objetos. Fernández -que funde

Dicha proposición, por cierto, sigue de cerca los razonamientos de Michel Foucault en Vigilar y castigar (2000), trabajo en el que despliega sus convicciones respecto de las múltiples tecnologías para la regulación de la conducta de los individuos: la prisión, los asilos y los museos. De este modo, el archivo supone un intento de visibilizar/invisibilizar dimensiones configuradas de uno $\mathrm{u}$ otro cuadro de costumbres, en cuyo ejercicio de fuerza revela otra tensión o sobre-violencia, como nos lo muestra Marta Traba en El museo vacío (1958) recordando a Paul Valery: «Como el sentido de la vista se encuentra violentado por este abuso del espacio que constituye una colección, así la inteligencia no se ofende menos por una estrecha reunión de obras importantes. Cuanto más bellas son, cuanto más representan los efectos excepcionales de la ambición humana más singulares deben ser. Son objetos raros cuyos autores hubieran querido que fuesen únicos. Tal cuadro -pensamos a veces- mata a todos los que se encuentran alrededor» (51).

4 Para Eva Valcárcel en «De sobremesa de José Asunción Silva. Pintura, poesía y novela» (1998) la escritura de Silva «se revela como un texto crítico que constituye un espacio para la reflexión del intelectual modernista sobre algunos aspectos del arte, la filosofía y, en definitiva, la estética de fin de siglo» (60). La autora desarrolla además la cercanía del poeta colombiano con el contexto romántico y moderno, donde enfatiza la influencia de Baudelaire a partir de sus profundas inclinaciones a las artes plásticas y destaca, además, la estética prerrafaelista de los cuadros de mujeres presentes en la novela, en que «la literatura y la pintura se unen aquí, en la necesidad de explicar la relación que con el mundo tiene Fernández y cuál es su experiencia del amor y del arte. Fernández, protagonista de la obra, lo es también de un discurso sobre el arte y el artista finisecular» (66).

5 Cristóbal Pera en «José Asunción Silva: un coleccionista hispanoamericano en París» (1996) amplía lo expuesto cuando declara: «En De sobremesa se ejemplifica de manera alegórica el dilema que perseguía a los hombres de letras hispanoamericanos de su tiempo: la situación cultural de unos países que le obligaban a convertirse en coleccionistas del catálogo que les ofrecía la cultura europea. En mi opinión, la novela refleja tal situación como un callejón sin salida en la derrota final del personaje, que no ha encontrado un su periplo europeo, ni en esa «decoración» en que se mueve en su interior parisino, esa identidad que tan afanosamente se ha dedicado a buscar» (122).

6 Sobre el mito de París o «complejo de París» en la novela de Silva, recomendamos el artículo «José Asunción Silva, escritor americano» (2010) de Francisca Noguerol. 
los límites entre vida y arte (Valcárcel 62) - es un fetichista acérrimo y un coleccionista convulso de toda clase de objetos, los cuales trae de Europa con el fin de remedar en su país el esplendor artístico que tanto admiró en sus viajes ${ }^{7}$. Creemos que esto último es una cuestión especialmente relevante si consideramos que el coleccionismo fue una práctica importante en la consolidación de la cultura europea y una manifestación de poder, gesto que el poeta desea replicar en su país natal. Las colecciones de José Fernández intentan instalar en Colombia el espíritu burgués europeo justificado, al menos en términos culturales y políticos, desde la conformación de múltiples colecciones y singulares tesoros y rarezas.

El adorador del arte y de la ciencia que ha juntado ya ochenta lienzos y cuatrocientos cartones y aguas-fuertes de los primeros autores antiguos y modernos, milagrosas medallas, inapreciables bronces, mármoles, porcelanas y tapices, ediciones inverosímiles de sus autores predilectos, tiradas en papeles especiales y empastadas en maravillosos cueros de oriente. (Silva 42)

Sin embargo, nuestro personaje no tiene el interés de recuperar, restaurar o memorizar el pasado significativo ausente, sino construir uno a la medida, desestimando el relato nacional vernáculo acumulado hasta entonces. El afán de "poseerlo TODO» confunde y desorienta desde el momento en que la más auténtica sensibilidad anula su proyecto racionalista.

Todo toma a mis ojos interesantes y sublimes aspectos, quería verlo, tenerlo, abrazarlo, besarlo todo, y confundido con todo, morir, no importa cuando, dentro de dos o dentro de treinta años, morir en un éxtasis para sentir el último misterio, el fin de todo o ese principio de una vida nueva. Para ser feliz necesito TODO, el resto no me basta! (Silva 39)

Esta apetencia contrasta con el gesto europeo, ya que en el coleccionismo latinoamericano propuesto no es posible sancionar la

Para Fernando Aínsa este gesto de mirar hacia el exterior es al menos significativo en las letras latinoamericanas. En Identidad cultural de Iberoamérica en su literatura (1986) sostiene que «... la meta de estos viajes, en lugar de encontrarse en el interior de América, lleva a la Europa de donde provenimos y con la cual se identifica una forma idealizada del Paraíso de los orígenes» (214). 
superioridad de un objeto sobre otro, es decir, la curatoría (criterio de «escogencia de todo eso» (51) señalará la novela) será impracticable, lo que da origen al desenfreno y a la acumulación. El texto de Silva al no jerarquizar los objetos, ni en términos de su mérito, ni de su pertenencia, al desestimar el valor diferencial entre lo propio y lo ajeno, hace trastabillar el sueño de conformación nacional asentado en bases aparentemente firmes del poder del coleccionista, burgués, blanco, civilizado y liberal.

Al respecto, María Mercedes Andrade, académica colombiana a quien tuve el agrado de escuchar en XVII Congreso de la Asociación de Colombianistas «Narrar Colombia: Colombia narrada», realizado en la Universidad Industrial de Santander en 2011, sostiene, ahora en su texto, «Una personalidad «proteica y múltiple»: modernidad, colección e identidad en De sobremesa» (2009), que esa ausencia de jerarquía tiene que ver con una carencia respecto del modelo europeo que intenta seguir:

La colección de objetos de Fernández, con su desorden, su ausencia de jerarquías y su rechazo de cualquier norma, implicaría lo que dentro de un contexto como el descrito por Clifford se categorizaría como una relación 'salvaje' hacia el objeto. Caótico y desenfrenado, Fernández es un mal coleccionista según los parámetros europeos de la colección de finales del siglo XIX y comienzos del XX, descritas por Benjamin y Clifford (párr. 23).

Por cierto, para nosotros la idea de «mal coleccionista» no da cuenta de los alcances de la acumulación que pretendemos enfatizar.

\section{Coleccionar, curatoriar, narrar}

José Fernández es un coleccionista - «sediento de todos los saberes y de todos las experiencias, esto es, un filósofo in nuce» (Gutiérrez Girardot, «José Fernández» 625)-que satura y recarga todo a su alrededor con la ingenuidad de un recolector refinado ${ }^{8}$ de fetiches de múltiple y contradictoria originalidad y valor, aun cuando ésta no sea la única o principal intensión como él mismo apunta cuando señala que sus viajes por el mundo le han servido para «almacenar sensaciones e ideas» (44).

Jean-Louis Déotte en ¿Qué es un aparato estético? Benjamín, Lyotard, Rancière (2012) define el lugar del criterio estético en el mundo del arte desde Kant: «... el juicio estético no trataba sobre el arte, sino más bien sobre un objeto de naturaleza coleccionable» (9). 
El acto de coleccionar objetos - esa «extraña forma de comportamiento» (Benjamin 223)- denota el interés, aunque desestimado en su real valía por el poeta/personaje, por construir una especie de identidad cultural en principio y una identidad nacional en el fondo a partir de la adopción, la suma indiscriminada y la acumulación de objetos, cuadros, porcelanas, estatuillas de mármol, muebles, joyas, vestuario, licores, libros... etc., colecciones que si bien registran residencia de origen en Europa al insertarse por la fuerza en un medio distinto y con menor desarrollo en el oropel materialista, van resignificándose en la medida que se distancian del original con lo cual se va construyendo -aunque impostada- una identidad nueva, algo ilusoria en un comienzo, pero que luego de ser masticada y deglutida desde el bogotano prisma de Hernández se empodera como un rasgo definitorio de una identidad nueva trasplantada, que menosprecia cualquier manifestación vernácula debido al enceguecimiento total provocado por la experiencia del coleccionista con la milenaria Europa. El muestreo memorial realizado por el poeta, la curatoría del recuerdo percibida como «aliada del progreso ${ }^{9}$, cuya materialidad es la misma novela, se distancia en el momento en que la colección se transforma en pura acumulación, pérdida de referencias colectivas, ausencia de lógica articuladora de bloque, ausencia de guión museográfico, ausencia de taxonomía y jerarquía de los objetos, es decir, puro inventario, acopio y depósito, nada de hilo argumental y por lo tanto, pura heterogeneidad e inconciencia, descontrol de aquello constitutivo de la memoria, sus objetos, sus archivos, sus documentos, sus lugares.

[M]e he quedado sorprendido del número de objetos de arte y de lujo que insensiblemente he comprado en estos seis meses y los he remirado uno por uno, con cariño porque en lo futuro me recordarán una época de mi vida más noble que los últimos años. Tú irás a adornar el vestíbulo del hotel en París, enorme vaso etrusco que ostentas en tus bajos relieves hermosa

Halbwachs, Maurice. Los marcos sociales de la memoria (2004). Cabe, en este punto, recordar que el mismo Halbwachs considera que la práctica del recuerdo es un proceso imaginativo de reconstrucción en que las imágenes que advienen del pasado no son evocaciones reales de ese pasado sino representaciones de él. En su clásico La memoria colectiva (2004) señala: «Es posible que estas imágenes reproduzcan de manera inexacta el pasado, y que el elemento o la parcela del recuerdo, que antes se encontraba en nuestra mente, las expresen de manera más exacta: a los recuerdos reales se añade así una masa compacta de recuerdos ficticios» (28). 
procesión de ninfas, y por sobre las cabezas de carnero que forman tus asas, las orquídeas del trópico [...]; os cruzaréis en guerrera panoplia sobre la partesana, cincelada como una joya, vosotras, espadas árabes de polícromas empuñaduras [...]; contra lo desteñido de vuestros matices moribundos, antiguos brocateles pesados, sonreirán los dos cuadros de Gainsborough y de Reynolds que compré en la venta anterior. (Silva 140-141)

De este modo, la narración deviene inventario, instancia que ha su vez transforma la actividad de coleccionar en un acto reflejo, es decir, donde se colecciona por coleccionar sin curatoría, sin filtros, sin intencionalidad. Sin embargo, esta ausencia de método perfila aquello propio del contacto con el modelo europeo deconstruido por la novela modernista de ese «hombre-poeta sándwich» (Roggiano 567) que es José Asunción Silva.

De sobremesa, entonces, pretende escribir la memoria de los que vendrán, es decir, construir violentamente aquello que será reconocible por las generaciones venideras como natural e importante, a la vez que como un relato justificador de las certezas que la sociedad colombiana propone, a modo de inventario, como constitutivas de su singularidad. Especificidad que acumula fojas en el sentido propuesto por González Echevarría cuando subraya que «las ficciones del Archivo son narrativas que siguen buscando la clave de la cultura y la identidad latinoamericana» (238). Escribir, nombrar, tatuar la memoria de los porvenir sugiere

10 Sobre la posibilidad de controlar la memoria artística a partir del ejercicio museal recomendamos «Los museos de museos: utopías para el control de la memoria artística» (2000) de María Teresa Marín Torres. Las primeras líneas de su trabajo son extremadamente claras: «Como resultado del positivismo y del enciclopedismo que dominó el mundo de los museos desde finales del siglo XIX hasta los años posteriores de la Segunda Guerra Mundial, hubo una serie de personas u organizaciones que pensaron que era posible el control de la información procedente de las obras de arte, sobre todo de las gestionadas por los museos. Algunas de estas visiones utópicas fueron mucho más allá, imaginando museos de museos o atlas de la memoria como imaginarios de todo el arte existente. El único problema al que se presentaban estos visionarios era el escaso avance en las tecnologías de almacenamiento y difusión de la información, algo que, sin embargo, ya se podía prever gracias a los descubrimientos científicos del XIX. Este optimismo, típico del primer cuarto del siglo XX se dio en el terreno del arte, con la explosión de las vanguardias, sobre todo con el Futurismo, a pesar de su vena destructiva y su actitud claramente antimuseística» (124). En otra zona de este interesante problema Fernando Aínsa, en «Los guardianes del olvido: novelar contra el olvido» (2011), agrega que «[e]n esta perspectiva se inscribe la idea de que todo discurso narrativo es, antes que nada, una recreación que intenta preservar la memoria. A través del proceso de interacción y diálogo entre el presente y el pasado, en el «vaivén» de un tiempo al otro que toda narración propicia, se establece una relación coherente entre ambos, se define un sentido histórico de pertenencia orgánica inscrito en un devenir colectivo, local, nacional o regional. Gracias a esta relación intertemporal se preserva la memoria como hogar de la conciencia individual y colectiva y se crea el contexto objetivo donde se expresan modos de pensar, representaciones del mundo, creencias e ideologías» (14). 
precisamente lo que un dispositivo como el museo pretende sea su función: el control de la memoria ${ }^{10}$, la vigilancia de la misma, en términos muy similares al dispositivo engendrado por Bentham y utilizado por Foucault: el panóptico. El mismo González Echevarría en el penúltimo párrafo de su Mito y Archivo. Una teoría de la narrativa latinoamericana (2000), declara: «el Archivo no es un carnaval bajtiano, pero, si acaso lo es, ocurre dentro de los muros de la prisión de Foucault» (252).

Es en esta prisión donde se conserva aquello que se ha escogido como valioso para representar el pasado y proyectarlo al porvenir; pasado vernáculo reemplazado por colecciones foráneas que desea pasen a conformar aquello dado a llamar memoria colectiva, una construcción discursiva que intenta homogenizar a los individuos para eliminar toda aquella línea memorial subversiva del orden que se pretende imponer hacia el futuro bajo una estructura que manifiesta una clara «vocación de servicio» hacia ese mismo cuerpo social que le da sentido y a la que, de alguna manera transforma. $\mathrm{Al}$ respecto Luis Grau Lobo en «Territorio de Cambios: algunas conjeturas sobre museos y otras ilusiones» (2012) agrega: «... el museo es $-y$ no puede no serlo- una estrategia de supervivencia de grupo, el mecanismo-resistencia de la mirada de una comunidad» (76). Montar un museo, entonces, es un ejercicio de presión doble: del pasado que es curatoriado y del futuro que es construido a partir del ejercicio de coleccionar, práctica política ejercida por otros medios.

Ahora bien, parece interesante la proposición de Quatremère de Quince, rescatada por Didier Maleuvre en Museum Memories: History, Technology, Art (1999) cuando señala que al trasladar de lugar los monumentos, al recoger sus fragmentos y clasificarlos, agrupándolos en colecciones, en ese ejercicio de fuerza se construye una nación muerta, una tumba, se mata al arte en nombre de la investigación histórica, por lo tanto, no se escribe una historia sino un epitafio (17). José Fernández ilusoriamente pretende que Colombia se acerque al París experimentado por él años antes, intento que, como vemos, no llega a puerto fundamentalmente porque lo albergado en las colecciones del dandy forma parte de una memoria ajena, europea, asiática, del primer mundo, con la cual los intentos de inscribir a Colombia como una nación ilustrada, pujante, resuelta y progresista no se materializa porque la curatoría, la ficción del Archivo y el arte, son transplantados a la fuerza 
en un intento de imponer un relato, un pasado esplendoroso que lleva adosado un futuro igualmente ilustrado. En La arqueología del saber (2005), Michel Foucault, parece clarificarnos el panorama cuando señala

Digamos, para abreviar, que la historia, en su forma tradicional, se dedicaba a «memorizar» los monumentos del pasado, a transformarlos en documentos y a hacer hablar esos rastros que, por sí mismos, no son verbales a menudo, o bien dicen en silencio algo distinto de lo que en realidad dicen. En nuestros días, la historia es lo que transforma los documentos en monumentos, y que, allí donde se trataba de reconocer por su vaciado lo que había sido, despliega una masa de elementos que hay que aislar, agrupar, hacer pertinentes, disponer en relaciones, constituir en conjuntos. Hubo un tiempo en que la arqueología, como disciplina de los monumentos mudos, de los rastros inertes, de los objetos sin contexto y de las cosas dejadas por el pasado, tendían a la historia y no adquirían sentido sino por la restitución de un discurso histórico; podría decirse, jugando un poco con las palabras, que, en nuestros días, la historia tiende a la arqueología, a la descripción intrínseca del monumento. (11)

\section{Archivo, novela, saber}

«Como el archivo, la novela atesora saber» (62) apunta González Echevarría en el texto citado, con lo cual destaca precisamente que el trabajo que la escritura hace con los archivos pone en el centro del interés la ausencia de aquello que ha sido organizado y coleccionado: «Los archivos guardan los secretos del Estado; las novelas guardan los secretos de la cultura, y el secreto de esos secretos» (62). Por lo tanto, el ejercicio curatorial se transforma en una práctica de la memoria, en una actividad provocadora. ${ }^{11}$

En De sobremesa el acto de coleccionar se instala en una doble vertiente, por un lado es tematizado (colección de mujeres, oficios,

$11 \quad \mathrm{Al}$ respecto el destacado historiador Jacques Le Goff expresa bellamente que en los documentos se encuentra internalizada la finalidad de conmemorar el pasado, cuestión que percibe singularmente en los monumentos. Para mayores antecedentes recomendamos la lectura de «Documento/ monumento", capítulo tercero de la segunda parte de El orden de la memoria. El tiempo como imaginario (1991). 
objetos lujosos, armas, cuadros, tapices, etc.) y, por otro, materializado en la construcción misma del relato (yuxtaposición de escenas plásticas cargadas de espectacularidad, descripción detallada de inmuebles por sobre seres humanos, musealización de la acción, etc.) vía la utilización de la écfrasis ${ }^{12}$ como recurso descriptivo.

La articulación de estas perspectivas permite comprender que en el acto de coleccionar se logra rozar el fuego del placer de poseer ${ }^{13}$, a la vez que contribuye a problematizar el ingreso del hombre latinoamericano a la modernidad y la idea progresista de construcción nacional. La novela crea y marca el espacio donde se inventarea lo coleccionado como un territorio digno y ejemplar para pensar y planificar la (re)configuración de la nación ${ }^{14}$. Al respecto, no podemos olvidar la declaración de Pierre Nora en un pequeño apartado de Pierre Nora en Les lieux de mémoire (2009), «La nación», cuando apunta: «Quien dice nación dice conciencia de los límites, arraigamiento en la continuidad de un territorio, por lo tanto memoria» (49). El mismo historiador francés, en otro momento, enfatiza que los archivos van constituyendo entramados, estructuras soporte del pasado básicamente por ese desapego memorial consciente

12 Por écfrasis o ecfrasis (en griego antiguo, č́ $\phi \varrho \alpha \sigma \iota \zeta$, 'explicar hasta el final') se entiende la representación verbal de una representación visual. Con Umberto Eco «cuando un texto verbal describe una obra de arte visual» (110). Aunque se suele considerar una forma de descriptio el término se ciñe habitualmente a un uso más especializado por el que designa el ejercicio literario de descripción de un objeto de arte.

13 Concordamos con de idea de «deseo de poder» que manifiesta María Mercedes Andrade en el texto citado: «El deseo de poseerlo todo sobre el cual se fundamenta el coleccionismo en De sobremesa, es, por un lado, muestra de vigor y de voluntad o deseo de poder, pero, por el otro, apunta también a una carencia, pues semejante deseo debe por fuerza permanecer insatisfecho» (párr. 27). Sin embargo, en el desenfreno de la acumulación por sí misma, notamos que se pierde de vista la actividad de memorización del pasado tan cara a los ejercicios curatoriales propios del mundo de la plástica y cuyo norte describimos en el comienzo de esta escritura. El mismo personaje enfatiza su particular impresión al respecto cuando señala: «... en cuanto a mi vida de hoy, tú sabes bien que, aunque distinta en la forma de la que he llevado en otras épocas, su organización obedece en el fondo a lo que ha constituido siempre mi aspiración más secreta, mi pasión más honda: el deseo de sentir la vida, de saber la vida, de poseerla, no como se posee a una mujer de quien nos hacen dueños unos instantes de desfallecimiento suyo y de audacia nuestra, sino como a una mujer adorada, que convencida de nuestro amor se nos confía y nos entrega sus más deliciosos secretos» (11-12).

14 Benedict Anderson en su clásico Comunidades Imaginadas. Reflexiones sobre el origen y la difusión del nacionalismo (1993), revela una «gramática de los nacionalismos» (28) en que habría incurrido el Estado colonial del siglo XIX a partir de una paradoja: la creación de tres instituciones de poder (el censo, el mapa y el museo) que cambiaron de forma y función cuando los territorios colonizados ingresaron en la lógica capitalista de la reproducción mecánica: «Estas tres instituciones fueron el censo, el mapa y el museo: en conjunto, moldearon profundamente el modo en que el Estado colonial imaginó sus dominios: la naturaleza de los seres humanos que gobernaba, la geografía de sus dominios y la legitimidad de su linaje» (228-229). Nuestro José Fernández se encuentra precisamente en el momento de la duda y la tensión entre progresismo y conservadurismo, valorar lo extranjero y desestimar lo vernáculo. Desde nuestra perspectiva el coleccionista bogotano decide adoptar el modelo foráneo con el cual se siente más cómodo y en el que percibe mayores expectativas de futuro. 
de los sujetos: «Cuanto menos se vive la memoria desde lo interno, más necesita soportes externos y referentes tangibles de una existencia que solo vive a través de ellos: de allí la obsesión por el archivo» (26). La novela del colombiano, el manejo de la colección fetiche de Fernández, su proyecto de renovación nacional, se circunscribe en esta preocupación por los archivos que van refrendando una memoria trasplantada a la vez que va desplegándose un relato, una ficción nacional, a partir de la aparición de ese lugar de memoria: la colección de Fernández.

Una reflexión sobre el futuro nacional -«la transformación con que sueño» (Silva 68) dirá el narrador de la novela- pasa por la construcción de un proyecto político integral (social, económico y cultural) que declara el poeta colombiano a sus compañeros de mesa mientras lee su diario. Sin embargo ese sueño, en el que cree fervientemente, es de una ingenuidad abismante.

El texto del diario de Fernández, correspondiente al 10 de julio, es la unidad más extensa de la novela junto con el texto del 1 de septiembre que recoge su pluma luego de cinco meses sin registrar acontecimientos. Durante el relato de ese día, Fernández describe un proyecto utópico de impulso nacional a partir del enriquecimiento personal y de país sirviéndose de la exportación de las riquezas naturales y materias primas colombianas, en oposición a la importación de objetos foráneos valiosos. Él quiere exportar aquello que sí es definitorio de su país (la riqueza natural en sus múltiples formas), lo que demuestra el desprecio de lo verdaderamente local y nacional. Su confianza en el progreso vía desarrollo económico y vía «buena fe», aun cuando sea necesaria la fuerza para imponer el régimen, dialoga con la tópica decimonónica civilización y barbarie cuando expresa la imperiosa necesidad de «civilizar» su tierra a partir de la conformación de un «partido de civilizados» (Silva 62), el fomento de la agricultura, minería e industria dentro de las coordenadas de una economía liberal que, por cierto, demandará la educación y el perfeccionamiento de los nativos para lo cual se hace necesario promover también la «inmigración civilizada» para que se produzca la mezcla con las «tribus salvajes» (66).

Lo anterior parece una digresión de lo que realmente desarrolla la novela, no la acción sino el inventario. Sin embargo, cabe hacer un par de precisiones que unifican este episodio con el tema central de esta aproximación a De sobremesa. 
José Fernández también es coleccionista de virtualidades, práctica que va conformando una memoria a la medida para el porvenir que registra aquello que el curador/narrador ha escogido de manera tal de asegurar un futuro iluminado por el pasado aunque este sea impostado. Si nos detenemos en los usos verbales del personaje, por ejemplo, nos daremos cuenta de que también se encuentra trabajando en colecciones futuras, colecciones o declaración de intensiones no materializadas que, por supuesto, no llegarán porque muchos de sus sueños no resisten una lógica mínima en el contexto mundial en que se desenvuelve el personaje: «Si la comisión de ingenieros, mandada de Londres por Morrel Blundell, da un dictamen favorable, sobre las minas de oro que tengo casi negociadas con ellos y que en la mortuoria de mi padre se evaluaron en una suma insignificante, las minas me darán al vendérselas varios millones de dólares» (60). Los verbos nos ayudan a percibir la ingenuidad con que Fernández pretende construir una Colombia fuerte y moderna: «iré a pasar un mes (a estudiar el modelo de desarrollo de Estados Unidos) para ensayarlo luego en nuestra experiencia» (61), «recorreré», "pasaré unos meses», «me instalaré en», «En dos años de consagración y de incesante estudio habré ideado un plan de finanzas racional», «os estudiaré monstruosas máquinas de guerra» (81), etc., etc... La acumulación, entonces no se detiene. El museo pensado como receptáculo de objetos dignificados en el pasado se proyecta ahora al futuro donde el intelectual, artista e iluminado José Fernández desplegará la sapiencia, tan ilusoria como refinada, que consagraría un proyecto renovador en Colombia que pasa por un aprecio desmedido por objetos de tradición trasplantada, a la vez que desprecio y olvido de la cultura material e inmaterial de un país que tiene cómo forjarse desde el aprecio por sus productos, su riqueza natural invaluable y los tiempos particulares de emancipación y desarrollo nacional.

Las colecciones lo inundan todo, arte y vida se funden a nivel de anular cualquier otra preocupación no vinculada a la acumulación. El texto presta enorme atención a las colecciones del poeta quien inclusive, al decir de sus contertulios, ahogan, apremian y sofocan a Fernández de tal modo que los objetos inanimados lo determinan en términos vitales.

¿Quieres saber qué es lo que no te deja escribir? El lujo enervante, el confort refinado de esta casa con sus enormes 
jardines llenos de flores y poblados de estatuas, su parque centenario, su invernáculo donde crecen, como en la atmósfera envenenada de los bosques nativos, las más singulares especies de la flora tropical. ¿Sabes qué es? No son tanto las tapicerías que se destiñen en el vestíbulo, ni los salones suntuosos, ni los bronces, los mármoles y los cuadros de la galería, ni el gabinete del extremo oriente con sus sederías chillonas y sus chirimbolos extravagantes, ni las colecciones de armas y de porcelanas, ni mucho menos tu biblioteca ni las aguafuertes y dibujos que te encierras a ver por semanas enteras. (Silva 14)

Como vemos, la narración prácticamente se vuelve enumeración e inventario de objetos. La minuciosidad de las descripciones refleja la intensidad de la influencia del modelo europeo de coleccionismo que Fernández quiere seguir para acercarse al modelo ideal. La recolección, el inventario, la conservación y la exhibición de bienes muebles convertidos en fetiches (Dujovne 14) va generando una zona sagrada, un espacio museal que venera el pasado y sus productos, un sitio convertido en un templo al que se debe asistir a admirar por su extraordinaria capacidad de justificar e interrogar el pasado para luego construir el futuro. De esta manera los observadores (espectadores y lectores) -que a decir de Silva deben ser artistas (17) - entienden que ya existe interés por reformular $\mathrm{u}$ orientar, en términos ideológicos y políticos, el desarrollo de una nación, por lo tanto, son otros (los poderosos) los responsables del futuro. García Canclini (1995), recordando a Marta Dujovne apunta que «los museos son unas de las instituciones donde más se inhibe la acción social» (7), aun cuando, los curadores (en nuestro caso José Fernández) manipulan la historia (diario de vida), la editan, la descifran y la exhiben para cumplir un programa ideológico. Maurice Blanchot en «El museo, el arte y el tiempo» (1976) describe la percepción de Paul Valery sobre el museo cuando señala que éste era un lugar «donde veía soledades encerradas que participan de la naturaleza del templo y del salón, la escuela y el cementerio» (19).

El museo comienza así a consagrarse como un dispositivo (Castilla, 2010) que selecciona, reúne, conserva, hospeda y sanciona aquello que culturalmente es valioso y que forma parte de lo que es definido como patrimonio inmaterial. Américo Castilla en «El museo como 
construcción política» ${ }^{15}$ agrega que «en sus colecciones se encuentran las evidencias materiales de todos los enunciados que componen el cuerpo de la cultura, sus indicios y sus marcas» (17) ${ }_{1}^{16}$ con lo cual abre una discusión francamente apasionante que dice relación con que aquello resguardado y prestigiado como valioso es material primero y último de una construcción discursiva particular (archivo/enunciado) -parte de un proyecto mayor en algunos casos ideológico, en otros político y en otros utópicos- marcada por las estructuras de poder que orientan o inducen ciertas interpretaciones acomodaticias de los posibles significados de las obras coleccionadas e inmovilizadas en sus pinacotecas, por lo tanto, la labor curatorial pareciera la continuación de una actividad política por otros medios.

\section{Conclusiones}

Las colecciones, entonces, exponen, además de los objetos eminentes, representativos y cuya dignidad amerite su vigencia en el futuro, la violencia en la conformación del corpus donde es posible reconocer su posición como piezas de culto definidas por beldades más allá de su materialidad, relegada a posiciones inferiores a favor de la consagración de la esfera simbólica que facilita una instrumentalización de los objetos en direcciones tan múltiples como contradictorias.

Podemos notar, entonces, cómo la dimensión estática del museo (y sus colecciones, en boga durante el XIX) que los considera verdaderos cementerios de piezas fosilizadas, carentes de significado, «mudos y aislados» (Castilla 17) en espera de cultos paseantes, se rompe en el momento en que percibimos la novela de Silva en las coordenadas expuestas ${ }^{17}$.

15 Para mayores antecedentes recomendamos la lectura de «Las políticas del museo» $\mathrm{y}$ «El Louvre, el olvido de la división» capítulos clave de Catástrofe y olvido. Las ruinas, Europa, el Museo de Jean Louis Déotte (1998).

16 En este mismo contexto no podemos olvidar la osada proposición de Douglas Crimp en On the Museum's Ruins (1993) al señalar que los museos son dispositivos de encierro así como las prisiones solo que los primeros encapsulan contenidos, archivos, enunciados: «Foucault analizó las instituciones modernas de reclusión -el asilo, la clínica, y la prisión- y en sus respectivas formaciones discursivas -locura, enfermedad y criminalidad-. Hay otra institución de reclusión esperando el análisis arqueológico -el museo- y otra disciplina -la historia del arte-» (Crimp 48; traducción propia).

17 Alfonso Reyes, en la década del 20 del siglo pasado, ya había puesto el acento en la desarticulación de esta imagen arquitectónica cuando propone en «Contra el museo estático» (1924) dinamizar el mausoleo, rompiendo la verticalidad de las relaciones propuestas por ese organismo cultural de modo que incluso las miradas de los visitantes o espectadores de las exhibiciones pudieran convertirse en un motivo plástico, y por lo tanto, exponible en ese recinto desacralizado. 
El texto suprime la distancia entre colección y coleccionista. La lectura del diario de José Fernández que privilegia la descripción de los objetos como práctica hedonista máxima reflejada en esa «pasión loca por el lujo en todas sus formas» (Silva 144), contrasta con el instintivo deseo de ponerse a la altura de aquellos bienes dignos de conservación y contemplación, vale decir, él también se exhibe en esta dinámica museal, es un cuadro más de esta exposición virtual, un cuadro con múltiples variaciones ${ }^{18}$ que lo retrata siguiendo el mismo tratamiento de la descripción de las colecciones, a saber, mediante la enumeración, la suma y el catálogo de sus atributos. Recordemos apenas algunas formas adoptadas por esta personalidad «proteica y múltiple, ubicua y cambiante» (Andrade párr. 15): adorador del arte, coleccionista, científico, hombre sensual, asceta, filósofo, místico, gastrónomo, bohemio, geólogo, hombre de negocios, poeta, soldado, etc. «Es ridículo. Escribo e involuntariamente cedo a mis exageraciones» (42).

Las colecciones de Fernández dicen relación con las distintas facetas del dandy colombiano, de tal modo que la exhibición de ellas necesariamente es una proyección del coleccionista obsesionado cuya «camisa está muy cerca de ser la camisa del hombre feliz» (Darío 12), comentario de Rubén Darío hacia José Lázaro, uno de los coleccionistas más célebre a comienzos del siglo $\mathrm{XX}$, y que retrata de cuerpo entero a nuestro José Fernández.

Al cierre, quisiéramos señalar que el estudio sistemático de las relaciones entre literatura y plástica no es importante solamente por el conocimiento multifocal de nuestra tradición cultural, sino por la capacidad de observación y agenciamiento distinto que tienen las disciplinas espaciales. En este contexto, el trabajo con la noción de archivo y su montaje particular en la novela proyecta una línea de trabajo interesante si damos por sentado que la memoria se construye a partir de una curatoría discursiva que se materializa en el acto de narrar. Con Andrea Pagni, en Memoria, duelo y narración. Chile después de Pinochet: Literatura, cine, sociedad (2004), se puede afirmar que: «La memoria

18 Multiforme dirá María Mercedes Andrade en «Una personalidad «proteica y múltiple»: colección, modernidad e identidad en De sobremesa» (2009). Singularidad que se manifiesta en que nuestro «protagonista es prácticamente un reflejo de los objetos mismos» (párr. 10), por lo tanto, suprime, como hemos señalado arriba, la distancia entre colección y coleccionista. 
colectiva se configura en el acto de narrar, que es un modo de volver público el recuerdo individual y ponerlo a dialogar con otros recuerdos en una elaboración colectiva del duelo por una experiencia colectiva perdida» (34). Pensar el museo y las colecciones desde la literatura nos permitirá, entonces, relativizar los criterios de autoridad de aquellas instituciones que se han instalado como organismos republicanos sostenedores de un proyecto de nación, como la gran institución del quehacer cultural (Lopes, 2010) a la vez que reconocer cierta dimensión museal en la literatura latinoamericana.

\section{Referencias bibliográficas}

Aínsa, Fernando. Identidad cultural de Iberoamérica en su literatura. Madrid, Gredos. 1986.

_. «Los guardianes de la memoria: novelar contra el olvido». Cuadernos Americanos, vol. 3, no.137, 2011, pp. 11-29.

Anderson, Benedict. Comunidades Imaginadas. Reflexiones sobre el origen y la difusión del nacionalismo. México, Fondo de Cultura Económica, 1993.

Andrade, María Mercedes. «Una personalidad «proteica y múltiple: modernidad, colección e identidad en De sobremesa». La Habana elegante, no. 46, 2009, En línea http: / / www.habanaelegante. com/Fall_Winter_2009/Dossier_Andrade.html

Benjamin, Walter. Libro de los pasajes. Madrid, AKAL, 2005.

Blanchot, Maurice. La risa de los dioses. Madrid, Taurus, 1976.

Castilla, Américo. «El museo como construcción política». El museo en escena. Política y cultura en América Latina. Buenos Aires, Paidós, 2010.

Blom, Philipp. El coleccionista apasionado. Una historia intima. Barcelona, Anagrama, 2013.

García Canclini, Nestor. «Presentación». Entre musas y musarañas. Una visita al museo. Autor Marta Dujovne. México D.F., Fondo de Cultura Económica, 1995, pp. 7-11.

Crimp, Douglas. On the Museum's Ruins. London, The MIT Press, 1993. 
Darío, Rubén. «Una casa museo». Don José Lázaro (1862-1947) visto por Rubén Darío y Miguel de Unamuno. Valencia, Castalia, 1951.

Déotte, Jean-Louis. Catástrofe y olvido. Las ruinas, Europa, el Museo. Santiago, Cuarto Propio, 1998.

- ¿Qué es un aparato estético? Benjamín, Lyotard, Rancière. Santiago, Metales Pesados, 2012.

Dujovne, Marta. Entre musas y musarañas. Una visita al museo. México D.F., Fondo de Cultura Económica, 1995.

Eco, Umberto. Mouse or rat: Translation as negotiation. London, Orion Books, 2003.

Foucault, Michel. Arqueología del saber. Buenos Aires, Siglo XXI Editores, 2005.

García Maffla, Jaime. «Silva, José Asunción». Diccionario enciclopédico de las letras de América Latina. Caracas, Biblioteca Ayacuyo, 1995.

González Echevarría, Roberto. Mito y archivo. Una teoría de la narrativa latinoamericana. México, Fondo de Cultura Económica, 2000.

Grau Lobo, Luis. «Territorio de cambios: algunas conjeturas sobre museos y otras ilusiones». Construcciones y usos del pasado. Patrimonio arqueológico. Territorio, museo. Valencia, Museu de Prehistòria de València, 2012.

Gutiérrez Girardot, Rafael. Modernismo. Supuestos históricos y culturales. Bogotá, Fondo de Cultura Económica, 1987.

. «José Fernández Andrade: un artista colombiano finisecular frente a la sociedad burguesa». Obras Completas. Edición crítica Héctor H. Orjuela. Madrid, ALLCA XX / Fondo de Cultura Económica, 1996.

Halbwachs, Maurice. La memoria colectiva. Traducido por Inés SánchezArroyo. Zaragoza, Prensa Universitaria de Zaragoza, 2004.

__. Los marcos sociales de la memoria. Traducido por Manuel Antonio Baeza y Michel Mujica. Barcelona, Anthropos, 2004.

Hernández, Francisca. «Evolución del concepto de museo». Revista General de Información y Documentación, vol. 2, no.1, 1992, pp. 85-97. 
Le Goff, Jacques. «Documento/monumento». El orden de la memoria. El tiempo como imaginario. Barcelona, Paidós, 1991.

León, Aurora. El museo. Teoría, praxis y utopía. Madrid, Cátedra, 2010.

Lopes, María Margaret. «Compartir espacios, colgar ballenas y apoyar a las universidades. El museo en escena. Política y cultura en América Latina». Buenos Aires, Paidós, 2010.

Maleuvre, Didier. Museum Memories: History, Technology, Art. California, Stanford University Press, 1999.

Marín Torres, María Teresa. «Los museos de museos: utopías para el control de la memoria artística». Imafronte, no. 15, 2000, pp. 123-144.

Noguerol, Francisca. «José Asunción Silva, escritor americano». Biblioteca Virtual Universal. 2010. En línea: http:/ / www.biblioteca.org.ar/ libros/154974.pdf

Nora, Pierre. Pierre Nora en Les lieux de mémoire. Santiago, LOM Ediciones, 2009.

Pagni, Andrea. Memoria, duelo y narración. Chile después de Pinochet: literatura, cine, sociedad. Alemania, Vervuert Iberoamericana, 2004.

Pera, Cristóbal. «José Asunción Silva: un coleccionista hispanoamericano en París». Cuadernos Hispanoamericanos, no. 556, 1996, pp. 115126.

Reyes, Alfonso. «Contra el museo estático». Calendario. Madrid, Cuadernos literarios, 1924.

Roggiano, Alfredo. «Poética y estilo en José Asunción Silva». Obra completa, Edición crítica de Héctor H. Orjuela. Buenos Aires, ALLCA XX / Fondo de Cultura Económica, 1996.

Silva, José Asunción. De sobremesa. Bogotá, Panamericana Editorial, 1997.

Tombón, Daniel. «Sueños de otro mundo: arte, modernidad y dinero en José Asunción Silva». Estudios de Literatura Colombiana, no. 27, 2011, pp. 77-95.

Traba, Marta. El museo vacío. Bogotá, Ediciones Mito, 1958. 
Valcárcel, Eva. «De sobremesa de José Asunción Silva. Pintura, poesía y novela». Thesaurus, Tomo LIII, no. 1, 1998, pp. 60-78.

Valery, Paul. Piezas sobre arte. Madrid, Visor, 1999. 